\title{
LEARNING, DEVELOPMENT, AND HOME DIGITAL MEDIA USE AMONG 6 TO 8 YEAR OLD CHILDREN
}

\author{
Genevieve Marie Johnson \\ Curtin University, Perth, Australia \\ E-mail: g.johnson@curtin.edu.au
}

\begin{abstract}
Young school children commonly use a range of digital media technologies including television, video games, and the Internet. Parents of 40 children in first and second grade completed a questionnaire that queried: 1) demographics, 2) number of home digital media devices, and 3) extent and nature of child use of those devices. Teachers who taught these first and second grade students completed a rating scale on the school achievement and developmental ability of participating children. The pattern of correlations among measures of child achievement/ability and measures of teacher-reported internet literacy and parent-reported home digital media use suggests that internet use has many positive associations and that playing video games and watching television have some negative associations. For example, children's mathematics skills were postively correlated with use of the Internet but negatively correlated with televsion viewing. In some cases, children who used the Interent alone appeared more competent than children who used the Internet with an adult. Digital media use during childhood is a complex phenonema with a range of potential outcomes. Simplistc approaches are counterproductive.
\end{abstract}

Key words: child development, children, digital media, internet, internet co-use.

\section{Introduction}

In an increasingly digitalized society, young school children commonly use a range of media technologies, most notably, television, video games, and the internet (Hofferth, 2010). American children aged 6 to 11 years spend more than 28 hours each week watching television and two hours and 23 minutes playing video games (McDonough, 2009). One in six Australian children aged 6 to 7 years have a television in their bedroom (Rutherford, Bittman, \& Biron, 2010). In 2009, 90\% of 5 to 7 year olds in Britain had home access to digital television, $78 \%$ had home access to the internet, and $84 \%$ had home access to a video game console (Ofcom, 2010). In a sample of Canadian 6 to 8 year olds, $49 \%$ reported using the internet to play games sometimes while $32.5 \%$ reported using the internet to play games often (Johnson, 2010a) According to Roberts and Foehr (2008), digital media consumption spikes during the late preschool period, decreases during the early school years, and then rises again at approximately 8 years of age. Use of electronic technologies during the early school years is particularly important to child development, learning, and subsequent patterns of digital media use (Johnson, 2010b). 
Although a large body of empirical research has addressed the developmental and educational consequences of television viewing during childhood, findings are collectively complex and subject to interpretation (Livingstone, 2009; Rutherford et al., 2010). For example, based on a comprehensive review of recent research, Mitrofan, Paul, and Spencer (2009) concluded that there was insufficient, contradictory, and methodologically flawed evidence on the association between television viewing and aggression in children. Similarly, Moses (2008) reviewed the research on the effect of television on young children's literacy and concluded that: 1) moderate amounts of television viewing were beneficial for reading, 2) the content of programs viewed by children was important, 3) programs that aim to promote literacy in young children positively impacted early literacy skills, and 4) there were limitations to the existing literature. Bases on review of 50 years of research, Schmidt and Anderson (2007) noted that there was no relationship between television viewing and reading achievement after third grade. Likewise, television viewing after 3 years of age has not been linked to attention problems (Zimmerman \& Christakis, 2007).

Consistent with research on the effect of television on children, the educational and developmental consequences of playing video games are collectively complex and subject to interpretation (Johnson, 2010a; Steinkuehler, 2010). Van Deventer and White (2002) observed proficient 10- and 11-year-old video gamers and noted extremely high levels of self-monitoring, pattern recognition, and visual memory. DeBell and Chapman (2006) concluded that internet use promotes cognitive development in children, "specifically in the area of visual intelligence, where certain computer activities -- particularly games -- may enhance the ability to monitor several visual stimuli at once, to read diagrams, recognize icons, and visualize spatial relationships" (p. 3). Reportedly, at-home online learning and communicating (but not playing and browsing) were associated with advanced child development in expressive language and metacognitive planning (Johnson, 2009). Lee, Bartolic, and Vandewater (2009) found that, among young school-aged children, time spent reading was negatively related to time spent playing video games.

While playing video games appears to stimulate aspects of cognitive development, research also establishes links to distractibility, over-arousal, hostility, and aggression (Hofferth, 2010; Johnson, 2010a). Swing, Gentile, Anderson, and Walsh (2010) reported an association between playing video games and increased attention problems during childhood. Based on naturalistic observation in a day care setting, Bacigalupa (2005) observed that when children played video games, "their interactions with others were disjointed, rushed, and ineffective" (p. 25). Focus group interviews with children revealed the perception of over-arousal and loss of awareness of surroundings during video game playing (Funk, Chan, Brouwer, \& Curtiss, 2006). Anderson, Gentile, and Buckley (2007) concluded that "no matter how many risk and protective factors the child already has, playing violent video games still adds additional risk for future increased aggressive behaviour" (p. 141).

The internet provides children with opportunities to communicate, access information, and engage in interactive play. Theoretically, such uses of the internet stimulate cognitive and social development (Johnson, 2006; Young, 2007). Children who use the internet for learning and communicating demonstrated better language and metacognition than children who did not report such online behaviour (Johnson, 2010b). Fiorini (2010) concluded positive and enduring cognitive benefits of computer use during early childhood with some evidence of associations with proactive social behaviour. In a comprehensive review of the literature, McCarrik and Li (2007) concluded that young children who used computers, compared to those who did not, demonstrated significant and global developmental superiority.

Despite the increasingly apparent learning and developmental advantages of digital technologies, panic typically surrounds the introduction of new technologies, particularly in relation to children and youth (Baron, 2009). There are currently two conflicting public anxieties surrounding children and digital media; first, that the such technology may harm children, for example, by exposure to inappropriate content and sexual predators and, second, that children without digital experiences are cognitively and socially disadvantaged (Johnson, 2010a). Reconciliation of these two conflicting anxieties rests on school digital literacy programs and family mediation strategies. School digital literacy curriculum includes recognizing online marketing techniques, understanding that personal 
8 privacy must be protected, and handling inappropriate content (Media Awareness Network, 2008). However, because schools equally promote and control young children's use of digital media (Livingstone, Bober, \& Helpsper, 2005), the home media environment constitutes differential impact on developmental and learning outcomes during the early school years (Burnett \& Wilkinson, 2005).

Unlike school environments, homes differ widely in the availability of various media devices and the extent of parental control of young children's media use (Valcke, Schellens, Van Keer, \& Gerarts, 2007). As evidenced by the mounting literature on the digital divide, not all children have access to digital communication and information technologies (Livingstone \& Helpsper, 2007). Family socioeconomic status (SES) including parent education and family income is at the heart of the digital divide (Krebeck, 2010) and such family characteristics are linked to patterns of children's media use. Indeed, numerous researchers have concluded that differences in access to emerging technologies tend to reinforce and replicate existing social inequalities (Dutton \& Helsper 2007; Eynon, 2009; Green, Facer, Rudd, Dillon, \& Humphreys, 2005). In a comprehensive cross-sectional and longitudinal analysis of media use among children 5 to 8 years of age, Lee and colleagues (2009) found that family income significantly predicted children's use of new media such as a computer. Correspondingly, higher parental education has frequently been associated with less television viewing by children (Australian Communications and Media Authority, 2009; Baxter \& Hayes 2007). Low SES parents report putting a television in the room where their child sleeps to keep the child occupied, help the child sleep, and free up other televisions for other family members (Taveras, Hohman, Price, Gortmaker, \& Sonneville, 2009). In a laboratory setting, "both the quantity and the quality of parent-child interaction decreased in the presence of background television" (Kirkorian, Pempek, Murphy, Schmidt, \& Anderson, 2009, p.1350).

Johnson (2010b) examined the relationships between family characteristics, patterns of children's internet use, and cognitive development. Reportedly, family SES accounted for 5\% to 7\% of differences in child cognitive-developmental scores. In contrast, indices of home internet use accounted for $3 \%$ to $29 \%$ of differences in child cognitive-developmental scores. Meta-analysis confirms that the impact of SES on academic achievement is eroding over time (Sirin, 2005). Increasingly effective structures of social equalization (e.g., public education, quality day care, preschool interventions, and prenatal programs) and the expanding middle class create the need for more precise description of home environments. Home internet use may provide more useful information regarding cognitive development than family socioeconomic characteristics.

Parental mediation or restriction has been promoted as one of the important factors influencing children's media use. Vandewater, Park, Huang, and Wartella (2005) found that $67 \%$ of families had rules about the amount of time young children are allowed to watch television. Families with higher SES were more likely to have rules than those with lower SES (Lee et al., 2009). Cho and Cheon (2005) surveyed families and found that parents' perceived control, obtained through shared web activities and family cohesion, reduced children's exposure to negative internet content. Lee and Chae (2007) reported a positive relationship between parental mediation techniques (website recommendation and internet co-use) and children's educational attainment. Unfortunately, "parental supervision cannot adequately protect children who have integrated the Net most fully into their social lives, especially given the high premium that children place on the use of the Net to talk to friends and explore social roles" (Steeves \& Webster, 2008, p. 4).

\section{Research Focus and Question}

A considerable volume of research has established both positive and negative associations between home characteristics, digital media use, and children's development and learning. Such research has typically examined the relationships between children's use of one media device and a specific developmental or learning outcome. A comprehensive examination of the relationship between multiple variables is required. What is the relationship between number of home media devices (televisions, PCs with internet connectivity, and video gaming systems), extent and nature (alone, with another child or with an adult) of child use of those devices, family socioeconomic characteristics, and children school-based learning (i.e., reading, writing, mathematics and internet skills) and developmental outcomes (i.e., cognitive, social, emotional and physical)? 


\section{Sample of Research}

Parents and teachers of students in first and second grade attending a school in western Canada were invited to participate in a study. Forty of 46 children returned signed research participation consent forms and completed parent questionnaires. Of these children, 19 were in first grade and 21 were in second grade; 20 were male and 20 were female. Children ranged in age from 77 months to 101 months (mean 89 months, SD 6.7 months). Approximately $82 \%$ of mothers and $97 \%$ of fathers reported being employed (part-time or full-time). With respect to the sample of mothers, $3.4 \%$ reported not completing high school, $34.5 \%$ reported high school graduation or apprenticeship training, and $62.1 \%$ reported some college or university education. With respect to the sample of fathers, $9.7 \%$ reported not completing high school, $58.1 \%$ reported high school graduation or apprenticeship training, and $32.3 \%$ reported some college or university education.

\section{Instrument and Procedures}

Toward the end of the school year, a parent questionnaire was sent home with the children and returned to the school. In addition to demographic items (i.e., parent education and family income), the questionnaire contained items concerned with the home digital media environment including the number of devices (i.e., televisions, PCs with internet connectivity, and video gaming systems) and the extent of child use of those devices. Additionally, an item asked parents to indicate the proportion of time their child spent online: 1) alone or by themselves, 2) with an adult, or 3) with another child (instructions asked parents to ensure that the three percentages added to $100 \%$ of the child's at-home time online).

Having received parental permission, teachers who taught participating first and second grade students completed a 10-item rating scale on their perception of the school achievement (i.e., reading, writing, mathematics, and internet literacy) and developmental outcomes (i.e., emotional control, popularity, physical ability, creativity, maturity, and general ability) of participating children. Each item was rated by teachers on a 5-point scale ranging from 1 (very low) to 5 (very high).

\section{Data Analysis}

Correlational analysis determined relationships between home digital media characteristics and child school achievement and development. Pearson's product-moment correlation coefficients were used for analysis of interval data (i.e., parental level of education, family income, and number of home media devices) and Spearman's correlation coefficient rho was used for analysis of ordinal data (i.e., parent ratings of extent of child use of digital media devoices at home and teacher ratings of child school-based achievement and developmental abilities). Regression analysis attempted to predict social patterns of young children's internet use at home (alone, with another child, or with an adult as dependent variables) and home digital media characteristics and child school achievement and development as independent variables. According to Chow, Wang and Shao (2007), correlation and regression analyses require large samples to determine week or small correlations. That is, the moderate to strong correlations may emerge with relatively few subjects.

\section{Results of Research}

As presented in Table 1, participating families possessed, on average, approximately three television sets, three video gaming systems and two PCs with internet connectivity. Table 2 provides a summary of parent rating of the extent to which child used home media devices. While considerable variability was apparent, in general, participating children reportedly watched television for more than one but less than three hours each day, played video games for less than one hour each day and 
were rarely online at home. Table 3 describes parental rating of children's use of the Internet alone, with another child or with an adult.

Table 1. Parent description of home digital media environment: number of devices.

\begin{tabular}{ccccc}
\hline Number of Devices & Mean & Minimum & Maximum & Standard Deviation \\
\hline Televisions & 3.12 & 1 & 9 & 2.16 \\
Internet Connected PCs & 2.21 & 1 & 9 & 2.47 \\
Video Gaming Systems & 3.01 & 1 & 9 & 2.33 \\
\hline
\end{tabular}

Table 2. Parent description of home digital media environment: child use of devices.

\begin{tabular}{ccccc}
\hline Child Use of Devices & Mean & Minimum & Maximum & Standard Deviation \\
\hline Watches Television & 2.84 & 2 & 4 & 0.64 \\
Uses the Internet & 1.38 & 1 & 3 & 0.62 \\
Plays Video Games & 1.74 & 1 & 3 & 0.73 \\
\hline
\end{tabular}

Note: 1 = never/hardly ever; $2=<1$ hour a day; $3=1$ to 2 hours a day; $4=>2$ hours a day

Table 3. Percentage of time child uses the Internet alone or with others (\%).

\begin{tabular}{ccccc}
\hline Uses the Internet & Mean & Minimum & Maximum & Standard Deviation \\
\hline Alone or by themselves & 16.8 & 0 & 100 & 26.7 \\
With an adult & 65.0 & 0 & 100 & 37.6 \\
With another child & 18.2 & 0 & 80 & 26.3 \\
\hline
\end{tabular}

Descriptive statistics for the teacher ratings of child school achievement and developmental ability are presented in Table 4. In general, teachers rated children as slightly above average suggesting a teacher bias or a sample characteristics. It may be that teachers of young children tend to view children positively. Alternatively, it may be that children who participated in the study were, on average, slightly above average in terms of school-based achievement and developmental outcomes. Indeed, differences in parental consent have been identified as a major source of bias in sampling children (Pless, Hagel, Zhang, \& Magdalinos, 2011). Nonetheless, such bias appears modest and sufficient variably exists to result in meaningful analysis.

Table 4. Teacher rating of children's school achievement and developmental ability.

\begin{tabular}{lcccc}
\hline Rating Scale Item & Mean & Minimum & Maximum & Standard Deviation \\
\hline Reading Ability & 3.64 & 1 & 5 & 1.09 \\
Writing Ability & 3.44 & 1 & 5 & 0.97 \\
Math Ability & 3.69 & 1 & 5 & 0.89 \\
Internet Literacy & 3.21 & 2 & 5 & 0.57 \\
Ability to Control Emotions & 3.56 & 2 & 5 & 1.02 \\
Classroom Popularity & 3.67 & 2 & 5 & 0.74 \\
Physical Ability (e.g., gym) & 3.72 & 2 & 5 & 0.79 \\
Creativity (e.g., art) & 3.62 & 3 & 5 & 0.59 \\
Maturity & 3.69 & 2 & 5 & 0.73 \\
General Ability (e.g., memory) & 3.62 & 2 & 5 & 0.75
\end{tabular}

Note: 1 = very low; $3=$ average; $5=$ very high 
As presented in Table 5, family characteristics (parental level of education and family income) were consistently related to the number of home digital media devices (televisions, PCs with internet Volume 1, 2012 connectivity, and video gaming systems). Specifically, as number of home digital media devices tended to increase, parental level of education and family income tended to decrease. In correlating parental level of education, family income, and parent-reported child digital media use at home, only one significant relationship emerged. As maternal level of education tended to increased, child at-home video game playing tended to decrease $(r=-0.39, p<0.05)$. Parent-reported number of television sets strongly correlated with number of PCs with internet connectivity $(r=0.92, p<0.01)$ and number of video game systems $(r=0.80, p<0.01)$. Number of PCs with internet connectivity strongly correlated with number of video game systems $(r=0.91, p<0.01)$. One significant relationship emerged between number of parent-reported digital media devices and parent-reported child use of those devices. As number of PCs with internet connectivity increased, children's time playing video games tended to increase $(\mathrm{r}=0.41, \mathrm{p}<0.05)$.

\section{Table 5. Relationships between family characteristics and home digital media devices.}

\begin{tabular}{cccc}
\hline Number of Devices & Mother Education & Father Education & Family Income \\
\hline Televisions & $-0.63^{* *}$ & $-0.37^{*}$ & \\
Internet Connected PCs & $-0.72^{* *}$ & & $-0.40^{*}$ \\
Video Gaming Systems & $-0.52^{*}$ & $-0.46^{*}$ \\
\hline
\end{tabular}

Note: ${ }^{*} p<0.05 ;{ }^{* *} p<0.01$

There were four measures of children digital media use: parent-reported child home 1) use of the internet, 2) television viewing and 3) video gaming and 4) teacher rating of child internet literacy (one of the achievement/ability rating scale items). Table 6 presents the significant relations to emerge between these four measures of child digital media use and teacher rating of child school achievement and developmental ability. As can be seen and in general, children's internet literacy ratings were associated with all measures of school achievement and developmental ability. As teacher-reported internet literacy tended to increase, all aspects of child school achievement and developmental ability tended to increase. Similarly, as parental report of home internet use tended to increase, many aspects of teacher-reported school achievement and developmental ability tended to increase. As watching television tended to increase, mathematics achievement tended to decrease. As extent to which parents reported home video gaming tended to increase, teacher-reported level of child maturity tended to decrease. The moderate positive correlation between teacher rating of child internet literacy and parent-reported extent of child home internet use $(r=0.56, p<0.01)$ in combination with insignificant correlations between teacher rating of child internet literacy and parent-report of extent of child television viewing and video gaming suggests the validity of the four measures of children digital media use. No significant correlations emerged between parentreported number of home digital media devices and any measure of student school achievement and developmental ability. Teacher ratings of child school achievement and developmental abilities were highly inter-correlated (e.g., reading and writing ability $r=0.93$, reading and math ability $r=0.80$, $\mathrm{p}<0.01$ in both cases). Significant relations did not appear between 1) reading ability and popularity and creativity and 2) physical ability and emotional control and physical skills. There were no significant correlations between parent-report of the amount of time children spend at home using the internet, watching television, and playing video games.

Table 6. Relationship between child achievement/ability and home digital media use.

\begin{tabular}{|c|c|c|c|c|}
\hline Achievement/Ability & Internet Literacy & Uses Internet & Watches TV & Plays Video Games \\
\hline Reading Ability & $0.59^{* *}$ & & & \\
\hline Writing Ability & $0.65^{* *}$ & $0.41^{*}$ & & \\
\hline Math Ability & $0.59^{\star *}$ & $0.39^{*}$ & $-0.32^{*}$ & \\
\hline
\end{tabular}




\begin{tabular}{lcccc}
\hline Achievement/Ability & Internet Literacy & Uses Internet & Watches TV & Plays Video Games \\
\hline Ability to Control Emotions & $0.43^{* *}$ & & & \\
Classroom Popularity & $0.30^{*}$ & & \\
Physical Ability & $0.31^{*}$ & & \\
Creativity & $0.48^{* *}$ & $0.52^{* *}$ & $-0.34^{*}$ \\
Maturity & $0.54^{* *}$ & $0.33^{*}$ & \\
General Ability & $0.56^{* *}$ & $0.40^{*}$ & \\
\hline
\end{tabular}

Note: ${ }^{*} p<0.05 ;{ }^{* *} p<0.01$

According to parents, children most commonly used the internet at home with an adult $(65 \%$ of total use). To a lesser extent, children reportedly used the internet at home alone (16.8\%) or with another child (18.2\%). Table 7 summarizes the relationships between extent of home internet use alone or with another person and family/home characteristics. As family income tended to increase, children's use of the internet at home alone tended to decrease. As number of home digital media devices tended to increase, children's use of the internet alone tended in increase. Inverse correlations between family/home characteristics and using the internet with an adult or alone suggest the validity of results. Using the internet at home alone was positively correlated with teacher-reported child creativity $(r=0.46, p<0.05)$, maturity $(r=0.49, p<0.01)$, general ability, $(r=0.44, p<0.05)$, and internet literacy $(\mathrm{r}=0.46, \mathrm{p}<0.05)$. In stepwise regression analysis, home digital media characteristics and child achievement/ability failed to predicted child use of the internet with another child. Family income (Beta $=-0.785, \mathrm{t}=-5.32, \mathrm{p}<0.01)$ and child writing ability (Beta $=0.393, \mathrm{t}$ $=2.66, \mathrm{p}<0.05)$ predicted child home internet use alone (adjusted $\mathrm{R}^{2}=0.784, \mathrm{~F}(1,9)=18.60, \mathrm{p}$ $<0.01$ ). Number of home gaming systems (Beta $=-0.741, \mathrm{t}=-3.31, \mathrm{p}<0.01)$ predicted child home internet use with another adult (adjusted $\mathrm{R}^{2}=0.499, \mathrm{~F}(1,9)=10.95, \mathrm{p}<0.01$ ).

Table 7. Relationships between home characteristics and Internet co-use.

\begin{tabular}{|c|c|c|c|}
\hline \multirow{2}{*}{ Home Characteristics } & \multicolumn{3}{|c|}{ Child Uses the Internet at Home } \\
\hline & By Themselves & With an Adult & With a Child \\
\hline Mother Education & & $0.42^{*}$ & \\
\hline \multicolumn{4}{|l|}{ Father Education } \\
\hline Family Income & $-0.79^{\star *}$ & $0.52^{*}$ & \\
\hline Number of Televisions & $0.52^{* *}$ & $-0.52^{*}$ & \\
\hline Number of Internet Connected PCs & $0.48^{*}$ & $-0.48^{*}$ & \\
\hline Number of Video Gaming Systems & $0.58^{* *}$ & $-0.63^{* *}$ & \\
\hline \multicolumn{4}{|l|}{ Child Watches Television } \\
\hline Child Uses the Internet & $0.56^{* *}$ & & \\
\hline Child Plays Video Games & & & \\
\hline
\end{tabular}

Note: ${ }^{*} p<0.05 ;{ }^{* *} p<0.01$

\section{Discussion}

Considerable variably characterized the sample of children in terms of the number of digital media devices in their homes (Table 1) and the extent to which they used such devices (Table 2). All participating parents reported that their home contained at least one television set, one PC with internet connectivity, and one video gaming system; in at least one case, nine of each such devices were reported. Some children never or rarely used the internet at home while others were online for up to 2 hours each day. Such variability, despite small sample size $(n=40)$, revealed significant relations between family SES characteristics and, particularly, number of home media devices (Table 5). In general, as parental education and family income increased, number of parent-reported home 
digital media devices tended to decrease. The inverse relationships were most significant between maternal level of education and number of home digital media devices. Since details of the digital Volume 1, 2012 media devices were unknown, it may be that higher SES homes contain fewer but better devices. Bickham and colleagues (2003) noted that families with higher incomes can afford to purchase new digital media equipment such as the latest video and computer games and this, in turn, may affect children's choice of media to use during their leisure time. Correspondingly, lower SES families may have a relatively large collection of outdated digital media devices. Such an inference is supported by the strong correlations among number of home digital media devices and lack of significant relationships between number of devices and children's use of those devices, with one exception. As the number of PCs with internet connectivity increased, parent-reported amount of time that children spent playing video games tended to increase. Such a pattern of relationships suggests that children of lower SES use the internet to play video games more often than children of high SES. As has been suggested, SES variables such as parental education may be related to the type of television programs and online activities that children choose (Lee et al., 2009).

The pattern of correlations among measures of child achievement/ability and measures of teacher-reported internet literacy and parent-reported home digital media use (Table 6) suggests that internet use has many positive associations and that playing video games and watching television have limited negative associations. As teacher ratings of child internet literacy increased, teacher ratings of child achievement and ability tended to increase. Inter-correlation of teacher ratings suggests that the rating scale may measure a single construct such as general ability. Alternatively, since not all teacher ratings correlated (i.e., child physical ability and classroom popularity) and since variability was evident in ratings of school achievement and developmental outcomes (Table 2 ), teachers may have accurately rated individual differences in their young students. Significant correlations between parent-reported extent of child internet use at home and six of the ten teacherratings of student achievement/ability add credibility to the conclusion that internet use is associated with learning and developmental advantages for 6 to 8 year old children. Teacher ratings of child internet literacy significantly correlated with parent-reported extent of child internet use at home but not with extent of television viewing or video gaming. These three at-home child behaviours differ from each other and may have differential effects on children. As time spent watching television increased, teacher ratings of numeracy skills tended to decrease. As time spent playing video games increased, teacher ratings of maturity tended to decrease. Increasingly complex digital media technologies create increasingly complex patterns of relationships to children's school achievement and developmental outcomes.

For the current sample of young school-aged children, approximately two-thirds of home-based internet use occurred with an adult, $18.2 \%$ with another child, and $16.8 \%$ alone, according to parents (Table 3). No significant relationships emerged between any measured variables and child use of the internet at home with another child. Correspondingly, regression analysis with measured variables as the independent or predictor variables failed to explain any differences in the sample of young students with respect to using the internet at home with another child. Regression and correlation analyses, however, explained considerable differences among the sample of children with respect to use of the internet at home alone or with an adult.

In predicting variation, regression analysis does not include independent variables whose relationship is explained or subsumed by another independent variable. While several family/home characteristics correlated with the extent to which children used the internet alone (e.g., number of digital media devices), such relationships were explained by differences in family income. Family income accounted for approximately $41 \%$ of the differences in child use of the internet at home alone. As family income decreased, children tended to use the internet at home alone. Child writing ability, as rated by teachers, increased the amount of variance explained by family income. As children's writing ability tended to increase, use of the internet at home alone tended to increased. Family income and child writing ability explained almost $61 \%$ of the differences in amount of time children used the internet at home alone. Correspondingly, number of gaming systems explained approximately $25 \%$ of the difference in amount of time that children use the internet with another adult. As the number of home gaming systems increased, the amount of time that children used the internet with an adult tended to decrease. Among the sample of participating families, lower SES 
OF PSYCHOLOGY

IN THE $21^{\text {st }}$ CENTURY Volume 1, 2012

14

children used the internet alone more than higher SES children, although children rated highly by their teachers tended to use the internet alone more than children less highly rated. Young children's use of the internet alone may not necessarily be undesirable. The implications of such behaviour may depend upon child characteristics such as ability.

\section{Conclusions: Implications for Practice}

Results of the current investigation have implications for practice, most notably, the finding that various devices differ in patterns of associations with child achievement/ability and the finding of factors associated adult-child digital media co-use. Children's use of the internet at home, as rated by parents, and children's internet literacy, as rated by teachers, evidenced positive associations with school achievement (i.e., numeracy and literacy) and emotional, social, physical, and cognitive development. In contrast, television viewing and video gaming were negatively associated with child achievement and ability, albeit, modestly and infrequently. Digital media use reflects a diverse range of behaviours associated with equally diverse learning and developmental outcomes for young students. It is not simply the case that emerging technologies are superior, from learning and developmental perspectives, to entrenched technologies (e.g., television). Learning and developmental benefits of video gaming, a relatively new technology, were not supported by findings of the current investigation, on the contrary.

There is a pervasive assumption that young children's use of digital media is most beneficial and, indeed, safest when supported and protected by adult co-use. Results of the current investigation include significant positive relationships between teacher-rated child abilities (i.e., creativity, maturity, general ability, and internet literacy) and child use of the internet at home alone. Additionally, teacher-rated child writing ability explained some of the differences in children's use of the internet at home alone. Cognitive abilities prerequisite to effective utilization of emerging technologies constitute an implicit component of contemporary conceptualization of intelligence. Adult-child digital media co-use may be beneficial and necessary in many, but perhaps not all, situations. Internet use during childhood facilitates aspects of literacy and, as noted for the current sample of young students, the more children use the internet, the more they tend to use it alone. Enhanced security features, as opposed to restriction by adult co-use, particularly in the case of competent children, may facilitate potential child learning and development associated with internet use.

\section{References}

Australian Communications and Media Authority (2009). Use of Electronic Media and Communications: Early Childhood to Teenage Years: Findings from Growing Up in Australia: The Longitudinal Study of Australian Children (3 to 4 and 7 to 8-year-olds) and Media and Communications in Australian Families (8 to 17-year-olds), 2007. Canberra, NSW.

Anderson, C. A., Gentile, D. A., \& Buckley, K. E. (2007). Violent Video Game Effects on Children and Adolescents. New York: Oxford University Press.

Bacigalupa, C. (2005). The use of video games by kindergarteners in a family child care setting. Early Childhood Education Journal, 33, 25-30.

Baron, D. (2009). A Better Pencil: Readers, Writers, and the Digital Revolution. New York: Oxford University.

Baxter, J., \& Hayes, A. (2007). How four-year-olds spend their days: Insights into the caring context of young children. Family Matters, 76, 34-43.

Bickham, D. S., Vandewater, E. A., Huston, A. C., Lee J. H., Caplovitz, A. G., \& Wright, J. C. (2003). Predictors of children's electronic media use: An examination of three ethnic groups. Media Psychology, 5, 107-137.

Burnett, C., \& Wilkinson, J. (2005). Holy Lemons! Learning from children's uses of the Internet in out-ofschool contexts. Literacy, 39, 158-165.

Cho, C. H., \& Cheon, H. J. (2005) Children's exposure to negative Internet content: Effects of family context. Journal of Broadcasting and Electronic Media, 49, 488-509. 
Chow, S. C, Wang, H., \& Shao, J. (2007). Sample Size Calculations in Clinical Research. London: Chapman $\& \mathrm{Hall} / \mathrm{CRC}$.

DeBell, M., \& Chapman, C. (2006). Computer and Internet use by Students in 2003. National Center for Educational Statistics. U.S. Department of Education, Washington, DC. Retrieved 17/01/2011, from http:// nces.ed.gov/pubs2006/2006065.pdt.

Dutton, W. H., \& Helsper, E. (2007). The 2007 OxIS survey: The Internet in Britain. Oxford Internet Institute. University of Oxford.

Eynon, R. (2009). Mapping the digital divide in Britain: Implications for learning and education. Learning, Media and Technology, 34 (4), 277-290. doi:10.1080/17439880903345874.

Fiorini, M. (2010). The effect of home computer use on children's cognitive and non-cognitive skills. Economic of Education Review, 29, 55-72.

Funk, J. B., Chan, M., Brouwer, J., \& Curtiss, K. (2006). A biopsychosocial analysis of the video-game-playing experience of children and adults in the United States. Studies in Media and Information Literacy Education, 6 (3), Article Number 79. Retrieved 17/01/2011, from http://www.utpjournals.com/simile issue23/Funk1.htm.

Green, H., Facer, K., Rudd, T., Dillon, P., \& Humphreys, P. (2005). Personalisation and Digital Technologies. Bristol, UK: Futurelab.

Hofferth, S. L. (2010). Home media and children's achievement and behavior. Child Development, 81 (5), 1598-1619.

Johnson, G. M. (2009). At-home Internet behavior and cognitive development during middle childhood. Technology, Instruction, Cognition, and Learning, 6, 213-229.

Johnson, G. M. (2010a). Young children's Internet use at home and school: Patterns and profiles. Journal of Early Childhood Research, 8, 282-293.

Johnson, G. M. (2010b). Internet use and child development: The techno-microsystem. Australian Journal of Educational and Developmental Psychology, 10, 32-43.

Kirkorian, H. L., Pempek, T. A., Murphy, L. A., Schmidt, M. E. \& Anderson, D. R. (2009). The impact of background television on parent-child interaction. Child Development, 80, 1350-1359. doi:10.1111/j.14678624.2009.01337.x

Krebeck, A. (2010). Closing the digital divide: Building a public computing center. Computers in Libraries, $30(8), 12-15$.

Lee, S. J., Bartolic, S., \& Vandewater, E. A. (2009). Predicting children's media use in the USA: Differences in cross-sectional and longitudinal analysis. The British Journal of Developmental Psychology, 27 (1), 123 -143. doi:10.1348/026151008X401336.

Lee, S. J., \& Chae, Y. G. (2007). Children's Internet use in a family context: Influence on family relationships and parental mediation. CyberPsychology and Behavior, 10, 640-644.

Livingstone, S. (2009). Half a century of television in the lives of our children. The Annuals of the American Academy of Political and Social Science, 625, 151-163.

Livingstone, S., Bober, M., \& Helpsper, E. (2005). Internet Literacy among Children and Young People: Findings from the UK Children Go Online Project. London: LSE Research Online. Retrieved 17/01/2011, from http://eprints.lse.ac.uk/397/1/UKCGOonlineLiteracy.pdf

Livingstone, S., \& Helpsper, E. (2007). Gradations in digital inclusion: Children, young people and the digital divide. New Media \& Society, 9, 671-696.

McCarrick, K., \& Li, X. (2007). Buried treasure: The impact of computer use on young children's social, cognitive, language development and motivation. AACE Journal, 15 (1), 73-95.

McDonough, P. (2009). TV Viewing among Kids at an Eight-Year High. The Nielsen Company. Retrieved 17/01/2011, from http://blog.nielsen.com/nielsenwire/media_entertainment/tv-viewing-among-kids-atan-eight-year-high

Media Awareness Network (2008). Web awareness Canada-An Overview. Ottawa, ON. Media and Internet Education Resources. Retrieved 17/01/2011, from http://www.media-awareness.ca/english/special initiatives/web_awareness,

Mitrofan, O., Paul, M., \& Spencer, N. (2009). Is aggression in children with behavioural and emotional dif- 
OF PSYCHOLOGY

IN THE $21^{\text {st }}$ CENTURY Volume 1, 2012 ficulties associated with television viewing and video game playing? A systematic review. Child: Care, Health and Development, 35, 5-15. doi:10.1111/j.1365-2214.2008.00912.x

Moses, A. M. (2008). Impacts of television viewing on young children's literacy development in the USA: A review of the literature. Journal of Early Childhood Literacy, 8, 67-102.

Ofcom. (2010). UK Children's Media Literacy. London: UK. Retrieved 17/01/2011, from http://stakeholders. ofcom.org.uk/market-data-research/media-literacy/medlitpub/medlitpubrss/uk_childrens_ml

Penko, A. L., \& Barkley, J. E. (2010). Motivation and physiologic responses of playing a physically interactive video game relative to a sedentary alternative in children. Annals of Behavioral Medicine, 39 (2), 162-169. doi:10.1007/s12160-010-9164-x

Pless, B., Hagel, B., Zhang, X., \& Magdalinos, H. (2011). Different approaches to obtaining consent for followup result in biased samples. Injury Prevention, 17, 195-200. doi:10.1136/ip.2010.029652.

Roberts, D., \& Foehr, U. (2008). Trends in media use. Future of Children, 18 (1), 11-37.

Rutherford, L., Bittman, M., \& Biron, D. (2010). Young Children and the Media: A Discussion Paper. West Perth, WA: Australian Research Alliance for Children and Youth.

Schmidt, M., \& Anderson, D. (2007). The impact of television on cognitive development and educational achievement. In N. Pecora, J. Murry, \& E. Wartella (Eds.), Children and Television: Fifty Years of Research (pp. 65-84). Mahwah, NJ: Lawrence Erlbaum.

Sirin, S. (2005). Socioeconomic status and academic achievement: A meta-analytic review of research. Review of Educational Research, 75, 417-453.

Steeves, V., \& Webster, C. (2008). Closing the barn door: The effect of parental supervision on Canadian children's online privacy. Bulletin of Science, Technology \& Society, 28, 4-19.

Steinkuehler, C. (2010), Video games and digital literacies. Journal of Adolescent and Adult Literacy, 54, 6163. doi:10.1598/JAAL.54.1.7.

Swing, E. L., Gentile, D. A., Anderson, C. A., \& Walsh, D. A. (2010). Television and video game exposure and the development of attention problems. Pediatrics, 126, 214-221.

Taveras, E. M., Hohman, K. H., Price, S., Gortmaker, S. L., \& Sonneville, K. (2009). Televisions in the bedrooms of racial/ethnic minority children: How did they get there and how do we get them out? Clinical Pediatrics, 48 (7), 715-719. doi:10.1177/0009922809335667.

Valcke, M., Schellens,T., Van Keer, H., \& Gerarts, M. (2007). Primary school children's safe and unsafe use of the Internet at home and school: An exploratory study. Computers in Human Behavior, 23, 2838-2850. doi:10.1016/j.chb.2006.05.008.

Van Deventer, S. S., \& White, J. A. (2002). Expert behavior in children's video game playing. Simulation and Games, 33, 28-48.

Vandewater, E. A., Park, S. E., Huang, X., \& Wartella, E. A. (2005) No-you can't watch that. American Behavioral Scientist, 48, 608-623.

Zimmerman, F. J., \& Christakis, D. (2007). Associations between content types of early media exposure and subsequent attentional problems. Pediatrics, 120, 986-992.

Advised by Yulia Lakhvich, Belarusian State University, Republic of Belarus

Received: January 09, 2012

Accepted: January 25, 2012
Genevieve Marie Johnson $\mathrm{PhD}$, Senior Lecturer, School of Education, Curtin University, GPO U1987, 6845 Perth, Australia.

E-mail: g.johnson@curtin.edu.au

Website: http://www.members.shaw.ca/gen.johnson 